\title{
X-linked intellectual disability, Van Esch type
}

INSERM

\section{Source}

INSERM. (1999). Orphanet: an online rare disease and orphan drug data base. X-linked intellectual disability, Van Esch type. ORPHA:163976

X-linked intellectual deficit, Van Esch type is characterized by mild to moderate intellectual deficit associated with low birth weight, short stature, microcephaly and variable hypergonadotropic hypogonadism. 